\title{
Effect of Dialysis Modality on Bone Disease in Patient with End Stage Renal Disease
}

Saeed Abd Alwahab, Waleed Anwar, Mohammed Elsaeed Aboalfarh*, Mostafa Abd Elnasier

Internal Medicine Department, Faculty of Medicine, Ain Shams University,Egypt

*Corresponding Author: Mohammed Elsaeed Aboalfarh, Phone No.: (+2) 01021290981,

E-mail : dr_mohammedelsaeed@yahoo.com

\begin{abstract}
Background: The kidney has an important effect on minerals and bone metabolism in humans. Kidney is the target organ of many regulating hormones such as parathyroid hormone (PTH) and fibroblast growth factor-23 (FGF-23), also it activates vitamin D. Abnormalities in phosphorus, calcium, vitamin D and parathyroid hormone are common in patients with chronic kidney disease (CKD).

Objective: To compare the effect of online hemodiafiltration (HDF) dialysis versus high flux hemodialysis on bone markers.

Patients and Methods: The study was performed on 50 prevalent hemodialysis (HD) patients in Ain Shams University Specialized Hospital on high flux dialysis and were divided into 2 groups (group 1), 25 patients who continued hemodialysis with high flux dialyzer and (group 2), 25 patients who were shifted to online HDF. Bone specific alkaline phosphatase (BSAP), calcium, phosphorus, blood urea nitrogen (BUN), creatinine, sodium, potassium and blood hemoglobin were measured at the start of this study and after 4 months. Only Parathyroid hormone $(\mathrm{PTH})$ was measured at the end of the study in both groups.

Results: there was significant increase BSAP and significant reduction of phosphorus levels after 4 months with online HDF compared to high flux HD; $p$ value 0.036 and $<0.001$ respectively.

Conclusion: Online HDF has significant effect on bone markers and phosphorus clearance than high flux Hemodialysis but we need more prospective with longer durations studies to confirm this effects.
\end{abstract}

Keywords: Bone specific alkaline phosphatase, Hemodiafiltration, Hemodialysis, Parathormone, Phosphorus.

\section{INTRODUCTION}

Kidney is the target organ hormones that affect bone metabolism like parathyroid hormone and fibroblast growth factor-23. Also, it activates vitamin $\mathrm{D}$, which is very important for control of serum calcium and phosphorus ${ }^{(1)}$. Prevalence of chronic kidney disease (CKD) varies between different countries. But it mostly affects $10 \%$ of is a systemic condition affecting about $10 \%$ of populations worldwide ${ }^{(2)}$. Bone disease is a common morbidity in prevalent HD patients and it is the result of bone turnover abnormalities and the decrease of bone mineral density ${ }^{(3)}$.

In 2003, National Kidney Foundation defined renal osteodystrophy by triad of abnormal mineral metabolism, skeletal and extraskeletal manifestations of a group of bone disorders ${ }^{(4)}$ and this definition failed to be accepted globally. Therefore, the second Kidney Disease: improving Global Outcomes (KDIGO) controversies conference in 2005 established the term chronic kidney disease-mineral and bone disorder (CKD-MBD), which is defined as: A systemic disorder of mineral and bone metabolism due to CKD manifested by either one or a combination of the following, first, abnormalities of calcium, phosphorus, PTH, or vitamin D metabolism; second, abnormalities in bone turnover, mineralization, volume, linear growth; third, vascular or soft tissue calcification ${ }^{(5)}$.

The European Dialysis Working Group defined hemodiafiltration (HDF) as renal replacement therapy that combines both convective and diffusive removal of solute by ultrafiltration of $\geq 20 \%$ of the blood volume passing through a high flux dialyzer and maintaining fluid balance by non pyrogenic, sterile replacement fluid. In online HDF, large volumes of sterile substitution fluid are produced by online filtration of standard dialysate though a series of endotoxin and bacteria retaining filters ${ }^{(\mathbf{6})}$.

Aim of the present work was to comparing the effect of online hemodiafiltration versus hemodialysis using high flux dialyzer on bone markers and phosphorus clearance.

\section{PATIENTS AND METHODS}

The study was performed from April 2020 to August 2020 on 50 prevalent HD patients in Ain Shams University Specialized Hospital using high flux dialyzer divided into 2 groups, (group 1), 25 patients who continued hemodialysis with high flux dialyzer and (group 2), 25 patients who were shifted to online HDF.

Inclusion criteria: Prevalent hemodialysis patients for $\geq 6$ months, adults $\geq 18$ years, hemodialysis with high flux dialyzers, and dialysis via native arteriovenous fistula.

Exclusion criteria: Patients with vascular access complications, patients with bone disease e.g. fracture or malignancy, and history of blood transfusion and drug intake, which can affect bone metabolism as aluminum hydroxide) for 1 month prior to study. 
(Group 1) continued dialysis using high flux polysulfone membrane, 3 sessions /week, blood flow was $250-350 \mathrm{~mL} / \mathrm{min}$, dialysate flow was 800 $\mathrm{mL} / \mathrm{min}$ and unfractionated heparin was administered as an anticoagulant.

(Group 2) had 3 session of online HDF/week for 4 hours with post-dilution, volume of fluid substitution was more than 15 litres. Blood flow was usually $250-350 \mathrm{~mL} / \mathrm{min}$, dialysate flow was 800 $\mathrm{mL} / \mathrm{min}$ and unfractionated heparin was administered as an anticoagulant.

\section{Laboratory Investigations:}

- Blood samples were collected at baseline and after 4 months except PTH, which had single reading at the end of the study.

- Blood sample was taken just before initiation of the mid-week session except for BUN, which was drawn after hemodialysis from the arterial line of the hemodialysis system immediately before discontinuation of the extracorporeal circulation.

- Laboratory investigations included: serum creatinine, BUN, sodium, potassium, calcium, phosphorus and bone specific alkaline phosphatase (BSAP).

- Blood was taken without stasis. Venous blood samples were collected into $3.8 \%$ sodium citrate in 9:1 volume ratio.

- PTH, bone-specific alkaline phosphatase, calcium, phosphorus, hemoglobin, BUN, creatinine were measured by standard laboratory measured.

- BSAP were measured using an enzyme-linked immunosorbent assay and detection level range was $1.6-50 \mathrm{ng} / \mathrm{L}$.
- All samples were obtained on EDTA containing tube after collecting the samples, the serum was allowed to clot for 10-20 minutes at room temperature then centrifugation was done (at 2000-3000 RPM) for 20 minutes. Then supernatants were collected and stored at $-80^{\circ} \mathrm{C}$ for 4 months.

\section{Ethical approval and written informed consent:} An approval of the study was obtained from Ain Shams University Academic and Ethical Committee. Every patient signed an informed written consent for acceptance of the procedure.

\section{Statistical analysis}

Recorded data were analyzed using the statistical package for the social sciences, version 20.0 (SPSS Inc., Chicago, Illinois, USA). Quantitative data were expressed as mean \pm standard deviation (SD). Qualitative data were expressed as frequency and percentage. Independent-samples t-test of significance was used when comparing between means of the two groups and paired t-test to compare means of the same group before and after treatment. Mann Whitney $\mathrm{U}$ test was used for two-group comparisons in non-parametric data. Chisquare $\left(\mathrm{X}^{2}\right)$ test of significance was used in order to compare proportions between qualitative parameters. Probability (p-value) was considered significant if $<0.05$.

\section{RESULTS}

No significant difference was found between both groups as regard sex (Table 1).

Table (1): Comparison between both groups as regard sex

\begin{tabular}{|c|c|c|c|c|c|c|c|}
\hline \multirow{3}{*}{ Sex } & \multicolumn{6}{|c|}{ Group } & \multirow{3}{*}{ P-value } \\
\hline & \multicolumn{2}{|c|}{ Group 1} & \multicolumn{2}{|c|}{ Group 2} & \multicolumn{2}{|c|}{ Total } & \\
\hline & $\mathbf{N}$ & $\%$ & $\mathbf{N}$ & $\%$ & $\mathbf{N}$ & $\%$ & \\
\hline Male & 20 & 80.00 & 19 & 76.00 & 39 & 78.00 & \multirow{3}{*}{0.733} \\
\hline Female & 5 & 20.00 & 6 & 24.00 & 11 & 22.00 & \\
\hline Total & 25 & 100.00 & 25 & 100.00 & 50 & 100.00 & \\
\hline
\end{tabular}

There was no significant difference between both groups as regard age and PTH levels at the end of the study (Table 2).

Table (2): Comparison between group 1 and group 2 as regard age and PTH level at the end of the study

\begin{tabular}{|l|c|c|c|c|c|c|c|c|}
\hline \multicolumn{2}{|c|}{} & \multicolumn{5}{c|}{ Group } & \multirow{2}{*}{ P-value } \\
\cline { 3 - 10 } & \multicolumn{3}{|c|}{ Group 1(N=25) } & \multicolumn{3}{c|}{ Group 2 (N=25) } & \\
\hline Age & Mean \pm SD & 42.080 & \pm & 8.741 & 42.160 & \pm & 7.570 & 0.973 \\
\hline PTH & Mean \pm SD & 254.80 & \pm & 8.66 & 222.44 & \pm & 41.09 & 0.083 \\
\hline
\end{tabular}

As regard BSAP, there was significant difference between both groups at the end of the study. Also in group 2, there was significant difference in BSAP levels before and after initiation of HDF (Table 3). 
Table (3): Comparison between both groups as regard bone specific alkaline phosphatase at before initiation and at the end of the study

\begin{tabular}{|c|c|c|c|c|c|c|c|c|}
\hline \multicolumn{2}{|c|}{ BSAP } & \multicolumn{5}{c|}{ Group } & \multirow{2}{*}{ P-value } \\
\cline { 3 - 9 } & \multicolumn{3}{|c|}{ Group 1 (N=25) } & \multicolumn{2}{c|}{ Group 2 (N=25) } & 0.057 \\
\hline Before & Mean \pm SD & 179.20 & \pm & 11.13 & 241.000 & \pm & 21.82 & 0.036 \\
\hline After & Mean \pm SD & 144.80 & \pm & 8.01 & 114.800 & \pm & 8.64 & \\
\hline Differences & Mean \pm SD & -34.40 & \pm & 2.05 & -126.200 & \pm & 4.64 & \\
\hline Paired Test & P-value & \multicolumn{4}{|c|}{0.105} & \multicolumn{3}{|c|}{$<0.001 *$} \\
\hline
\end{tabular}

Table 4 shows no significant difference between group 1 and group 2 as regard calcium level either.

Table (4): Comparison between both groups as regard calcium level before initiation and at the end of the study

\begin{tabular}{|c|c|c|c|c|c|c|c|c|}
\hline \multirow{2}{*}{\multicolumn{2}{|c|}{ Calcium }} & \multicolumn{6}{|c|}{ Group } & \multirow{3}{*}{$\begin{array}{c}\text { P-value } \\
0.447\end{array}$} \\
\hline & & \multicolumn{3}{|c|}{ Group $1(\mathrm{~N}=25)$} & \multicolumn{3}{|c|}{ Group $2(N=25)$} & \\
\hline Before & Mean \pm SD & 9.01 & \pm & 0.68 & 9.15 & \pm & 0.65 & \\
\hline After & Mean \pm SD & 9.14 & \pm & 0.81 & 9.38 & \pm & 0.73 & 0.286 \\
\hline Differences & Mean \pm SD & 0.13 & \pm & 0.03 & 0.22 & \pm & 0.77 & \\
\hline Paired Test & P-value & \multicolumn{3}{|c|}{0.227} & \multicolumn{3}{|c|}{0.160} & \\
\hline
\end{tabular}

Table 5 shows significant difference at the end of the study. Also in group 2, there was significant difference in phosphorus level before and after initiation of HDF.

Table (5): Comparison between both groups as regard phosphorus level before initiation and at the end of the study

\begin{tabular}{|c|c|c|c|c|c|c|c|c|}
\hline \multirow{2}{*}{ Phosphorus } & \multicolumn{6}{|c|}{ Group } & \multirow{2}{*}{ P-value } \\
\cline { 3 - 9 } & \multicolumn{3}{|c|}{ Group 1 (N=25) } & \multicolumn{2}{c|}{ Group 2 (N=25) } & 0.78 & $0.083(\mathrm{NS})$ \\
\hline Before & Mean \pm SD & 4.59 & \pm & 0.88 & 4.18 & \pm & 0.76 \\
\hline After & Mean \pm SD & 4.10 & \pm & 1.05 & 2.87 & \pm & 0.36 & $<0.001$ \\
\hline Differences & Mean \pm SD & -0.49 & \pm & 1.31 & -1.30 & \pm & 0.87 & \\
\hline Paired Test & P-value & \multicolumn{3}{|c|}{0.073} & \multicolumn{3}{|c|}{$<0.001$} & \\
\hline
\end{tabular}

Table 6 shows significant difference at the end of the study. Also in group 2, there was significant difference in BUN level before and after initiation of HDF.

Table (6): Comparison between both groups as regard BUN level before initiation and at the end of the study

\begin{tabular}{|c|c|c|c|c|c|c|c|c|}
\hline \multirow{2}{*}{\multicolumn{2}{|c|}{ Bun }} & \multicolumn{6}{|c|}{ Group } & \multirow{3}{*}{$\begin{array}{c}\text { P-value } \\
0.119\end{array}$} \\
\hline & & \multicolumn{3}{|c|}{ Group $1(\mathrm{~N}=25)$} & \multicolumn{3}{|c|}{ Group $2(\mathrm{~N}=25)$} & \\
\hline Before & Mean \pm SD & 64.68 & \pm & 10.05 & 60.36 & \pm & 9.169 & \\
\hline After & Mean \pm SD & 64.56 & \pm & 10.5 & 52.52 & \pm & 6.04 & $<0.001$ \\
\hline Differences & Mean \pm SD & -0.12 & \pm & 13.43 & -7.84 & \pm & 5.42 & \\
\hline Paired Test & P-value & \multicolumn{3}{|c|}{0.965} & \multicolumn{3}{|c|}{$<0.001$} & \\
\hline
\end{tabular}

Table 7 shows no significant difference between group 1 and group 2 as regard creatinine level.

Table (7): Comparison between both groups as regard creatinine level before initiation and at the end of the study

\begin{tabular}{|c|c|c|c|c|c|c|c|c|}
\hline \multirow{2}{*}{ Creatinine } & \multicolumn{6}{c|}{ Group } & \multirow{2}{*}{ P-value } \\
\cline { 3 - 9 } & \multicolumn{3}{|c|}{ Group 1 (N=25) } & \multicolumn{3}{c|}{ Group 2 (N=25) } & \\
\hline Before & Mean \pm SD & 8.76 & \pm & 1.37 & 8.22 & \pm & 2.07 & 0.289 \\
\hline After & Mean \pm SD & 8.772 & \pm & 1.173 & 8.27 & \pm & 1.7 & 0.232 \\
\hline Differences & Mean \pm SD & 0.02 & \pm & 0.35 & 0.05 & \pm & 2.35 & \\
\hline Paired Test & P-value & \multicolumn{3}{|c|}{0.820} & \multicolumn{3}{c|}{0.920} & \\
\hline
\end{tabular}


Table 8 shows no significant difference between group 1 and group 2 as regard hemoglobin level.

Table (8): Comparison between both groups as regard blood hemoglobin level before initiation and at the end of the study

\begin{tabular}{|c|c|c|c|c|c|c|c|c|}
\hline \multirow{2}{*}{ Hemoglobin } & \multicolumn{6}{|c|}{ Group } & \multirow{2}{*}{ P-value } \\
\cline { 3 - 9 } & \multicolumn{3}{|c|}{ Group 1 (N=25) } & \multicolumn{2}{|c|}{ Group 2 (N=25) } & \\
\hline Before & Mean \pm SD & 10.332 & \pm & 1.213 & 10.93 & \pm & 1.737 & 0.163 \\
\hline After & Mean \pm SD & 10.116 & \pm & 1.426 & 10.76 & \pm & 1.65 & 0.146 \\
\hline Differences & Mean \pm SD & 0.216 & \pm & 0.649 & -0.17 & \pm & 1.32 & \\
\hline Paired Test & P-value & \multicolumn{3}{|c|}{0.109} & \multicolumn{3}{c|}{0.522} & \\
\hline
\end{tabular}

Table 9 shows no significant difference between group 1 and group 2 as regard sodium level.

Table (9): Comparison between both groups as regard sodium level before initiation and at the end of the study

\begin{tabular}{|c|c|c|c|c|}
\hline \multicolumn{2}{|c|}{ Sodium } & Group 1 (N=25) & Group 2 (N=25) & P-value \\
\hline Before & Mean \pm SD & $135.24 \pm 3.41$ & $137.04 \pm 2.93$ & 0.053 \\
\hline After & Mean \pm SD & $135.36 \pm 3.17$ & $136.96 \pm 3.07$ & 0.080 \\
\hline Difference & Mean \pm SD & $0.12 \pm 2.19$ & $-0.08 \pm 2.48$ & \\
\hline Paired t-test & P-value & 0.786 & 0.871 & \\
\hline
\end{tabular}

Table 10 shows no significant difference between group 1 and group 2 as regard potassium level, although in group 2, there was highly significant difference in potassium level before and after initiation of HDF.

Table (10): Comparison between both groups as regard sodium level before initiation and at the end of the study

\begin{tabular}{|c|c|c|c|c|}
\hline \multicolumn{2}{|c|}{ Potassium } & Group 1 (N=25) & Group 2 (N=25) & P-value \\
\hline Before & Mean \pm SD & $5.12 \pm 0.41$ & $5.06 \pm 0.41$ & 0.603 \\
\hline After & Mean \pm SD & $4.98 \pm 0.42$ & $4.85 \pm 0.39$ & 0.234 \\
\hline Difference & Mean \pm SD & $-0.14 \pm 0.63$ & $-0.21 \pm 0.26$ & \\
\hline Paired t-test & P-value & 0.294 & 0.001 & \\
\hline
\end{tabular}

\section{DISCUSSION}

Renal bone disease is one of the most common complications affecting prevalent hemodialysis patients. Many factors are involved in the pathogenesis of this condition, including hyperphosphatemia, alterations in vitamin $\mathrm{D}, \mathrm{PTH}$ levels, hypogonadism, amyloidosis, immobility, poor quality dialysis or diabetes mellitus ${ }^{(7)}$.

Online HDF is an option of renal replacement therapy that have significant benefits for HD patients. Hemodiafiltration have clinical advantages to the HD patient, including better hemodynamic and cardiovascular stability, enhanced removal of middle molecular weight toxins ${ }^{(\mathbf{8})}$.

In this study, the age and sex in the two groups were comparable with no significant $p$ value between both groups.

As regard BSAP, there was significant difference at the end of the study. Also in group 2, there was significant reduction in BSAP levels before and after initiation of $\mathrm{HDF}$, which indicates less bone turn over online HDF. This is against the study by Elsayed $\boldsymbol{e t}$ al. (9), in which there was no significant difference between high flux dialysis and online HDF as regard BSAP, which may be attributed to smaller sample size (32 patients) and shorter duration of the study (3 months).

Hyperphosphatemia is an independent risk factor for all-cause and cardiovascular mortality in hemodialysis (HD) patients. In this study the serum phosphorus level was significantly lower in online HDF group when compared with high flux dialysis group after 4 months. Also, in group 2, there was significant reduction of phosphorus level after shifting to online HDF. This agrees with the study of Penne $\boldsymbol{e t} \boldsymbol{a l} .{ }^{(\mathbf{1 0})}$, in which there was significant reduction of serum phosphorus after 6 months of online HDF.

On the other hand, there was no effect of online HDF on PTH level as shown by non-significant difference between both groups after 4 months. This is against the results of Orasan $\boldsymbol{e t}$ al. ${ }^{(11)}$ that showed significantly higher PTH level, which may be due to longer duration of online HDF (6 months).

This study shows that online HDF has better effect on small solute clearance when compared to high flux dialysis; there was significant reduction of BUN in online HDF group after 4 months.

On the other hand there was no significant difference between both groups as regard serum creatinine, sodium and potassium levels, which agrees 
with Hao et al. (12), who showed no significant difference between high flux dialysis and online HDF after 6 years.

In this work we didn't find any difference between both groups as regard blood hemoglobin levels. This is against Lee $\boldsymbol{e t}$ al. (13), who showed significant improvement in blood hemoglobin level in online HDF group compared to high flux $\mathrm{HD}$, which may be attributed to longer duration (24 months) and larger sample size.

\section{CONCLUSION}

Online HDF has significant effect on bone markers and phosphorus clearance than high flux hemodialysis but we need more prospective with longer durations studies to confirm this effects.

\section{REFERENCES}

1. Pavlovic D, Katicic D, Gulin T et al. (2015): Chronic kidney disease mineral bone disorder. Periodicum Biologorum., 117: 81-85.

2. Hill N, Fatoba S, Oke J et al. (2016): Global prevalence of chronic kidney disease-a systematic review and metaanalysis. PLoS One, 11:28-36.

3. Ketteler M, Block G, Evenepoel P et al. (2017): Executive summary of the 2017 KDIGO Chronic Kidney Disease-Mineral and Bone Disorder (CKD-MBD) guideline update: what's changed and why it matters. Kidney Int., 92(1):26-36.

4. Eknoyan G, Levin A, Levin N et al. (2003): K/DOQI clinical practice guide-lines for bone metabolism and disease in chronic kidney disease. Am J Kidney Dis., 42(4): 1-201.

5. Moe S, Drueke T, Cunningham J et al. (2006): Definition, evaluation, and classification of renal osteodystrophy: a position statement from Kidney
Disease: improving Global Outcomes (KDIGO). Kidney Int., 69(11):1945-1953.

6. Schiffl H (2019): Online hemodiafiltration and mortality risk in end-stage renal disease patients: A critical appraisal of current evidence. Kidney Res Clin Pract., 38(2):159-168.

7. Crisafulli A, Romeo A, Floccari F et al. (2005): Osteoprotegerin and bone mineral density in hemodiafiltration patients. Ren Fail., 27(5):531-539.

8. McCarthy J, Moran J, Posen G et al. (2003): A time for rediscovery: chronic hemofiltration for end-stage renal disease. Semin Dial., 16:199-207.

9. Elsayed H, Elsharkawy M, Kamel C et al. (2020): Effect of hemodiafiltration on sclerostin level and bone specific alkaline phosphatase in comparison with high flux dialysis. QJM: An International Journal of Medicine, 113 (1): 155-162.

10. Penne E, Weerd N, Dorpel M et al. (2010): Short-term effects of online hemodiafiltration on phosphate control: A result from the randomized controlled convective transport study (CONTRAST). Am J Kidney Dis., 55 (1): 77-87.

11. Orasan R, Patiu I, Anghel D et al. (2013): Variation of clinical and laboratory features in chronic dialysis patients treated with high-flux hemodialysis after switching to online hemodiafiltration. Int Urol Nephrol., 45 (5):14151422 .

12. Hao N, Yang C, Yang $H$ et al. (2019): Comparison of solute clearance, hospitalization rate, and aortic arch calcification between online hemodiafiltration and highflux hemodialysis: A 6-year observational study. Kidney Blood Press Res., 44(2):264-276.

13. Lee Y, Shin Y, Lee $\mathbf{S}$ et al. (2020): Effects of online hemodiafiltration on anemia and nutritional status in chronic hemodialysis patients. Kidney Res Clin Pract., 39 (1):103-111. 